\title{
Integrated and Effective Assessment Tool to Evaluate Engineering Courses
}

\section{Dr. Suleiman A. Ashur, Indiana University Purdue University, Fort Wayne}

Suleiman Ashur is a Professor of Civil Engineering and the Program Coordinator at Indiana UniversityPurdue University Fort Wayne. Dr. Ashur is a recipient of several honors and awards including the IPFW Student Organization Advisor of the Year ward, 2012 and 2013; Outstanding Teaching Award, the American Society of Engineering Education, Illinois-Indiana Section; IPFW Outstanding Academic Advisor Award, 2011; and Teacher of the Year Award, Sigma Xi: The Scientific Research Society, 2010. Dr. Ashur has been successful in publishing his research findings in scholarly referred journals and conferences and in attracting externally funded research contracts from state, federal, and international agencies. Dr. Ashur is a member of American Society of Engineering Education (ASEE), American Society of Civil Engineers (ASCE), and registered Professional Engineer in the States of Arizona and Texas.

Dr. Mohammad Alhassan, Indiana University Purdue University Fort Wayne 


\title{
Integrated and Effective Assessment Tool to Evaluate Engineering Courses
}

\begin{abstract}
The civil engineering program at Indiana University-Purdue University Fort Wayne was established in the fall of 2006. The program went through ABET accreditation in 2011 and was granted accreditation in August 2012. A key component of getting accreditation is the development and the implementation of an effective and continuous assessment based process to identifying strengths and weaknesses and to ensure continuous program improvements.
\end{abstract}

The goal of this paper is to present an integrated assessment tool to assess course outcomes based on direct and indirect assessment measures. The tool was developed to establish consistency in the course assessment process, improve efficiency, create a better documentation process, and measures the effectiveness of educational and learning of engineering courses.

The tool was developed using Excel and report the faculty and student assessments of a course. The tool is flexible and save faculty time when assessing their courses. It provides faculty with a choice to feed raw data or enter students' final assessment data in the sheet. In addition, it gives faculty a choice to use suitable criteria and assessment tools that are appropriate to the assessment of their courses.

The paper presents the old system of assessment and the need to depart to a new more efficient system; a detailed description of the tool with real examples, and the impact of the new tool in supporting ABET accreditation of the Civil Engineering program as well other programs in the department are presented.

\section{Introduction}

The Civil Engineering (CE) program started at Indiana University-Purdue University Fort Wayne (IPFW) in 2006; the only public program offered in the area that enables students to get excellent public education while living at home and attending school. In December 2008, the Civil Engineering Assessment Plan (CEAP) was developed and approved, based on the department's existing “one-assessment-plan-fits-all” format that was developed for all programs in 2004. The assessment plan requires intensive effort to implement and lacks consistency and documentation in some aspects of assessment. In order to meet the ABET requirements of assessment based improvement of the program, it was necessary to depart from this approach, and modify the current plan to take into consideration the individual needs of each program. Therefore, an integrated and effect assessment tool was developed to help in assessing course outcomes.

\section{Background}

The educational objectives and program outcomes of the Civil Engineering Program are assessed using direct and indirect tools. The direct tools are methods used to evaluate students' knowledge or skills against a measurable outcome by direct examination or observation of student 
performance. According to $\mathrm{ABET}^{1}$, the indirect assessments of student learning "ascertain the perceived extent or value of learning experiences. They assess opinions or thoughts about student knowledge or skills.” This paper addresses the course assessment including the faculty assessment form and procedure. In particular it presents the tool developed to measure the course outcome based on Faculty Course Assessment and Students Interim Assessment Forms.

The course assessment is conducted by the instructor and the students but, currently there is no mechanism to integrate both. There is a need to combine all course assessment in order to evaluate the curriculum. The following are recommendations were implement to improve the assessment process ${ }^{2}$ :

1) Integrate faculty and student course assessment: course assessment is conducted mainly by students and instructors. The students' evaluation is based on a survey that measures their perception of achieving course outcomes. However, the faculty assessment of the course evaluates the ABET outcome of the course. Usually, several course outcomes are mapped to the same ABET outcome. In order to establish consistency between the two assessments, it is recommended that instructors evaluate courses outcomes as well. In order to implement this recommendation, it is necessary to develop a new form to join the results of both assessments into one document.

2) The assessment process should be consistent: The old assessment process did not have any unified rules or guidelines for instructors to follow when evaluating the course ABET outcomes. Therefore, each course is evaluated differently based on a set of criteria set by the instructor. In most cases, the instructor reports that the course outcomes have been met without supportive evidence or documentations. The new course assessment tool was developed with well-defined criteria, evaluate course intended outcome, and follow the same guidelines. This will help in integrating course assessment into curriculum assessment.

3) Continuous improvement of courses: The assessment tool should contain recommendations from the instructor who taught the course last time and his recommendation to improve the courses in the future. The new instructor of the course should list what recommendation he implemented in the course and justification for not implementation others. The new instructor should add his comments as well to improve the course. This will guarantee a continuous improvement of the course with documentation of these improvements.

There are several methods to do assessment for courses. Some are sophisticated and requires heavy program like database or using the assessment tool within a learning management system such as Blackboard. However, due to the time limitation and cost related issue, the approach proposed in this paper was selected to due to the limitations in time and budget.

\section{Assessment of course outcomes}

The current assessment plan calls for assessing program outcomes based on course assessment conducted by instructors and students over a two-year period for all courses in the degree plan. Each course is evaluated at least one time. A course may be assessed more than one time in cases where one of the course outcomes or ABET outcomes are not met and where a course is taught by a faculty member or a limited time lecturer for the first time. The instructor who taught the 
course will provide recommendations to help in achieving and/or improving the course outcomes. These recommendations are shared with the instructor who is scheduled to teach the course in the next offering of the courses. In addition, students evaluate the course intended outcomes during the last week of each semester using the Course Outcome Survey.

The new assessment tool was developed using on the following steps:

1) Develop "Faculty Assessment of Course Form” and Analysis Tool: Figure 1 shows the first design of the new Faculty Assessment of Course Form, including the analysis tools. As shown in the figure, the proposed form is simple and easy to use. The form was developed using Excel and has a drop-down menu. The data in these forms was randomly generated. This form was first tested during the ABET visit to campus as a pilot study in fall 2011 semester.

2) Final "Faculty Assessment of Course Form" and Analysis Tool: Figure 2 shows the modified and final version of the new Faculty Assessment of Course Form based on the recommendation of pilot study and the concerns of the ABET team. The new form has the following modifications:

1) Criteria Definition: list of six criterions that can be used in course assessment were identified and approved by the department assessment committee. Each criterion has a thresh hold that each outcome should meet.

2) Criteria used: this section is used to list the criteria used in evaluating each course outcome. In addition, it has the value of the assessment of students based on the data needed by each assessment criteria. In case the results are very close to the threshold, then the faculty member chose "Yes, adequately" as a conclusion of a course outcome assessment. In case the results of the assessment is way above the threshold, then the result should be "Yes, strongly" that the course has been met. Any value below the threshold, then the course outcome was not met. The adequate rating should be above the threshold set by the assessment committee and shown in the assessment form. The range, is set by instructor of the course. However, and in order to maintain consistency among different section and courses, instructors are informed to consider a score of 5-10\% above the threshold to be adequate. Any score above this range is considered strongly met. Sample of these results are shown in Figure 2(a).

3) Continuous Improvement: three boxes contains: 1) Instructor comments on recommendation from previous assessment of the course, 2) Instructor Comments \& Observation on current semester, and 3) Recommendations to improve students' performance in achieving course learning outcomes in future offering. This section is critical to document recommendations for improvement, ensures continuous improvement among several faculty members teaching the course, and is an evidence of assessment based improvement. Table 1 present a sample of comments and recommendation compiled for the spring 2012 assessment of the course. ${ }^{4}$ Sample of these changes are shown in Figure 2(b).

4) Develop “Students Assessment of Course Form” Form: The old student survey asks students to evaluate each course outcome by choosing either "Yes" or "No" where yes indicates 
achievement of intended outcome and no as a failure. In contrast, the new form requires that the survey uses a 1-4 scale. The proposed analysis tool will map the survey results to ABET and program outcomes. A new Students Assessment of Course Form was developed and added to the faculty form. Sample of the form is shown in Figure 3. More details about the lab form that is currently under development will be presented in future publications.

The new tool was used fully in spring 2012. Several faculty members acknowledged the effectives and ease of use of the new system and recommended that the department replaces the old assessment tool with the new one.

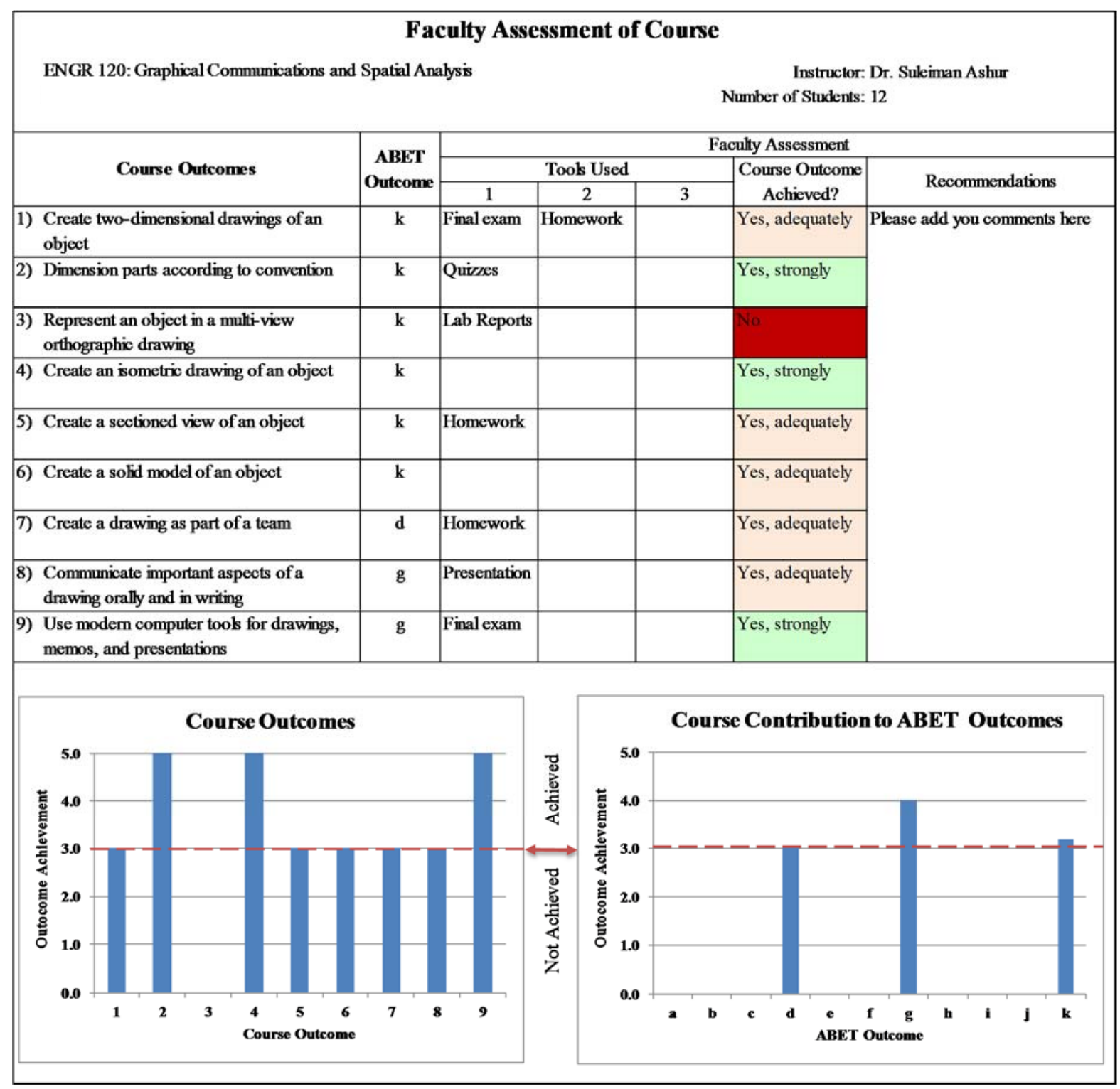

Figure 1: Initial Faculty Assessment of Course Form and Analysis Tool 


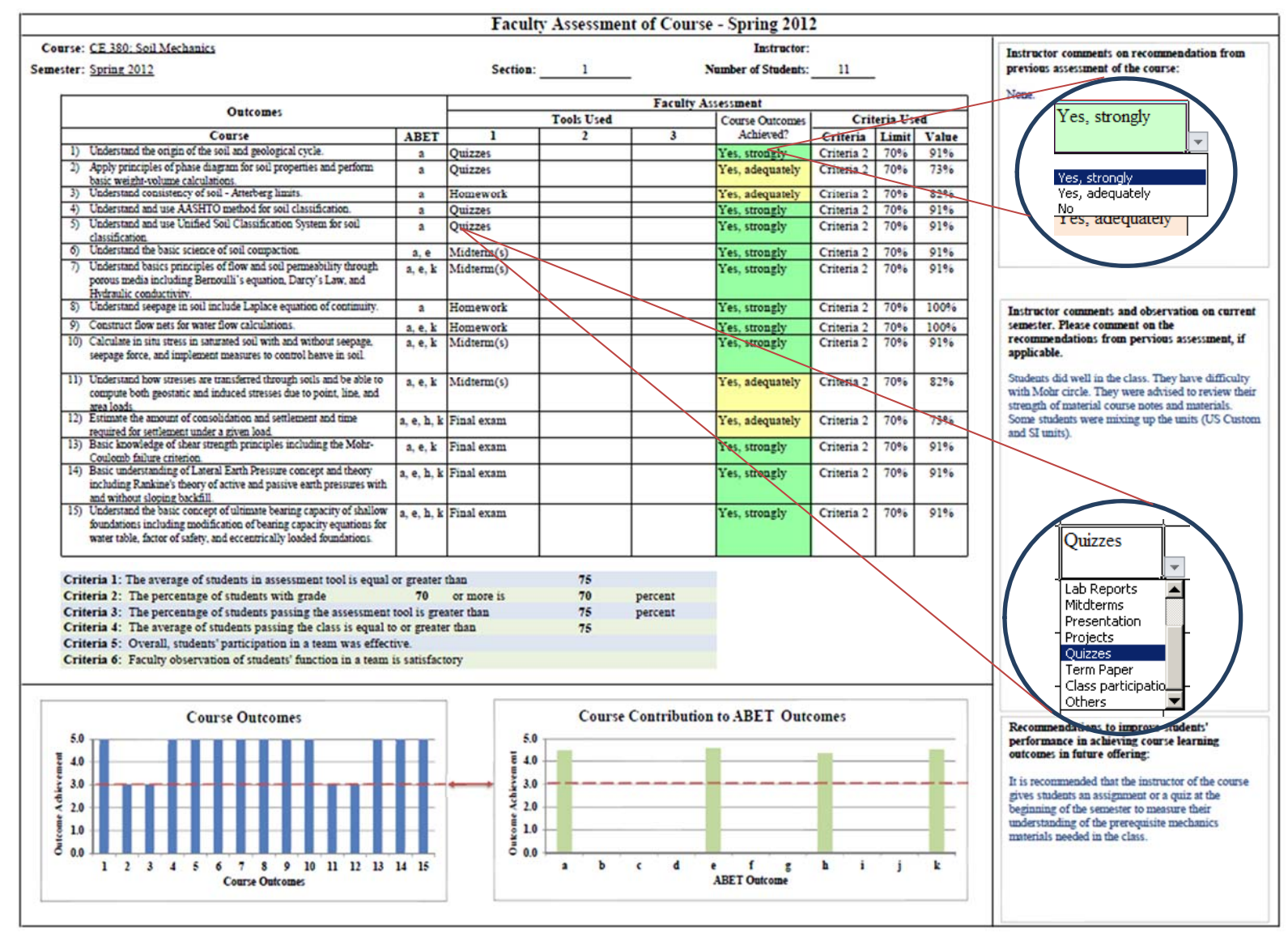

Figure 2 (a): Fall 2011 Faculty Assessment of Course Form and Analysis Tool. 


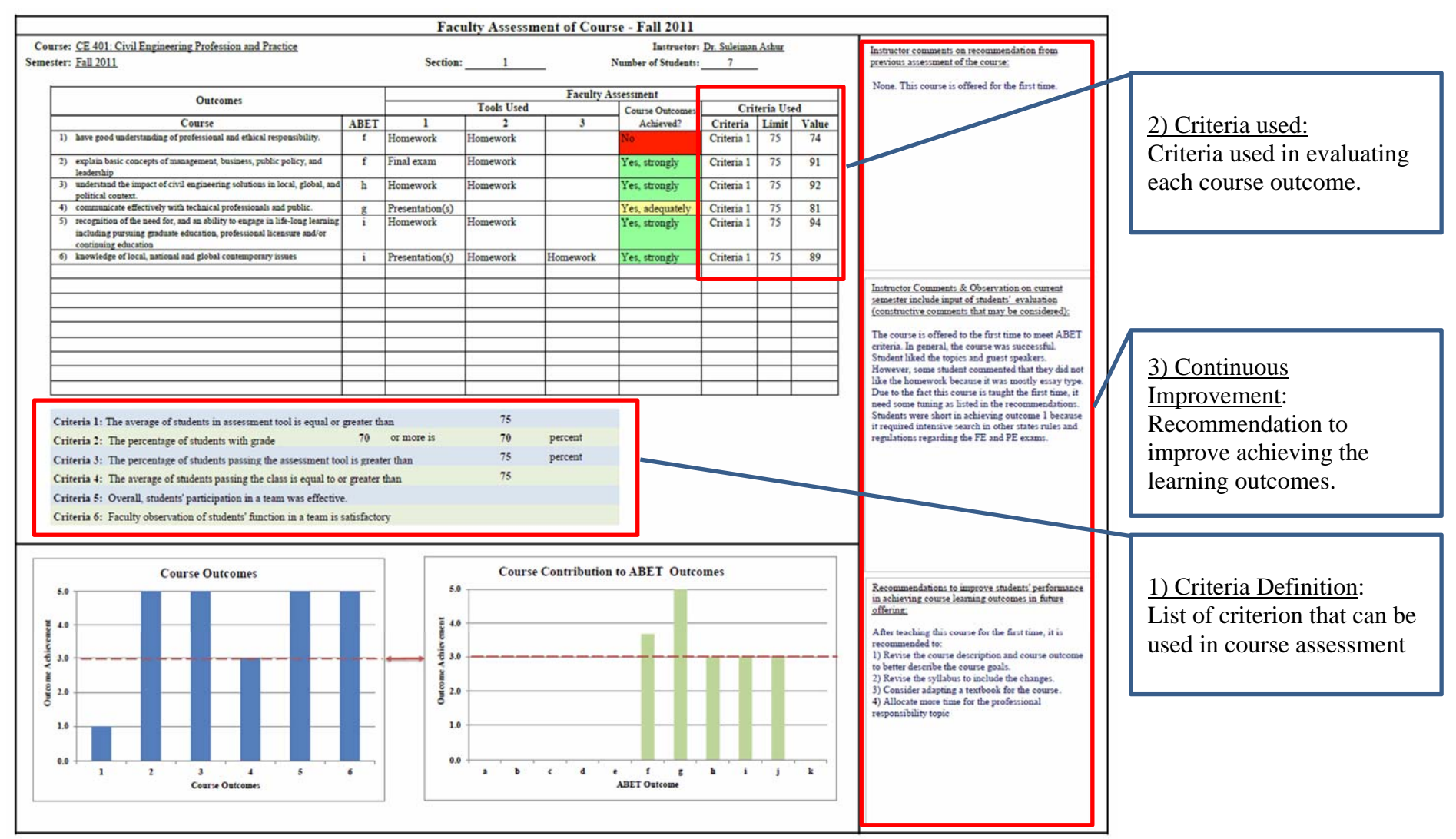

Figure 2 (b): Fall 2011 Faculty Assessment of Course Form and Analysis Tool 


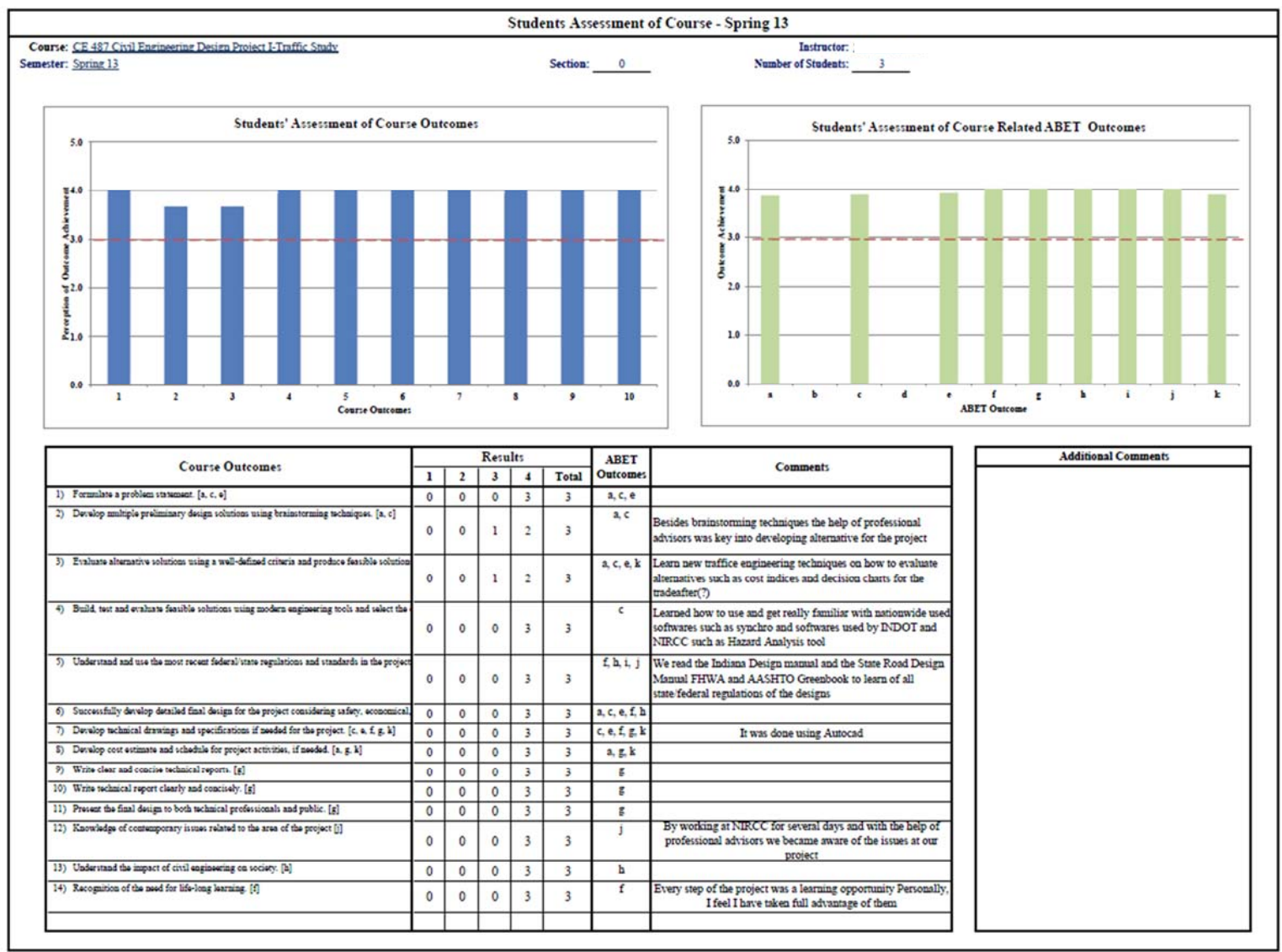

Figure 3: Student Assessment of Course Form and Analysis Tool 


\section{Table 1}

Sample of the faculty comments and recommendations for improvement, spring $2012^{4}$

\begin{tabular}{|c|c|c|}
\hline Course & Faculty Comments & Recommendation for Continuous Improvement \\
\hline $\begin{array}{l}\text { ENGR } \\
120\end{array}$ & $\begin{array}{l}\text { The students are at many different levels of } \\
\text { independence. Some students are ready for } \\
\text { college engineering; some still want their high } \\
\text { school teacher to walk them through } \\
\text { everything. } \\
\text { The course being taught in one long class } \\
\text { period works out well. Some students are not } \\
\text { ready for the testing and projects that come } \\
\text { with College. }\end{array}$ & $\begin{array}{l}\text { Have less homework problems and smaller projects. } \\
\text { This will keep the amount of work the same but } \\
\text { place more importance more spread out. }\end{array}$ \\
\hline CE 252 & $\begin{array}{l}\text { Quite a few of students are struggling about } \\
\text { the force analysis using free-body diagrams. }\end{array}$ & $\begin{array}{l}\text { It is recommended that: } \\
\text { - an instructor gives a review on free-body } \\
\text { diagrams at the beginning of the semester. } \\
\text { - Put more focus on free body diagram in Statics. }\end{array}$ \\
\hline CE 315 & $\begin{array}{l}\text { This course composed of } 11 \text { heavy chapters. } \\
\text { The students feel that it is too much } \\
\text { information for one course. They also believe } \\
\text { that taking the lab during the same semester } \\
\text { will help them better understand many of the } \\
\text { course subjects. } \\
\text { I agree with the students. However, the reason } \\
\text { for doing it this way because of our limited } \\
\text { resources in terms of CE faculty members. I } \\
\text { am the only instructor that can cover this } \\
\text { course and four other courses in the structural } \\
\text { \& concrete. }\end{array}$ & $\begin{array}{l}\text { I recommend splitting the course into two courses } \\
\text { as typically covered in similar courses in majority } \\
\text { of the other CE departments. }\end{array}$ \\
\hline
\end{tabular}

\section{Training and Evaluation of the Tool}

At the beginning of each semester, faculty members or adjunct faculty who never used the tool before are invited to attend a one hour training on how to use the new assessment tool. Faculty and limited time lecturer are encourage to ask questions and contact the authors with any problems or concerns. At the end of each semester, the authors get verbal input on the tool from faculty. Most of the comment are favorable of the new tool. Frequent comments include: easy to use, looks complicated but once you use it is really simple, it provides a comprehensive system that shows ABET outcomes, Course outcomes, and feedback that easy to follow, and much better than the old system.

The results and recommendations of each assessment are reviewed by the Department Assessment Committee. Summary of the recommendations are presented in the program assessment report along with recommendations and suggestions of the Chair of the Assessment committee and the faculty in the program. Some examples of continuous improved include the restructuring of the freshmen engineering program, upgrade of the labs, and change in the textbooks or modification to the material taught in a course.

\section{Summary and Recommendations}

This paper presents the new course assessment tool that is used in the Department of Engineering at IPFW. The new tool consists of two sheet: direct assessment of the course by faculty and indirect assessment of the course outcomes by students. The faculty found the tool to be easy to 
use, develops consistency among all courses, provides an analysis of assessed course and ABET outcomes, and provide comments for future instructor to ensure continuous improvement.

However, there is a need to develop similar spreadsheet for the lab assessment. Currently, the lab assessment results are tabled as shown in figure 4.

The key component of an effective assessment process is to develop an assessment system that leads to continuous improvement of educational outcomes and objectives. In addition, it is critical to use the results of assessment in any modifications and changes in order to create an assessment based improvement system. It is recommended that programs evaluate frequently their assessment process and plans in order to find ways to make it simple and more efficient. Faculty members acknowledge the ease of use and effectives of the new tool. As a result, the new tool was adopted and replaced the old tools of assessment. This tool played a critical role in helping creating a system of continuous improvement of course outcomes.

\section{Bibliography}

1. Accreditation Board for Engineering and Technology (ABET). (2006). 2007-2008 Criteria for Accrediting Engineering Programs. Retrieved January 5, 2007 from http://www.abet.org/forms.shtml

2. S. Ashur, Civil Engineering Assessment Plan, Department of Engineering, Indiana University-Purdue University Fort Wayne, December 2008.

3. S. Ashur, Civil Engineering Program Assessment Report: Spring 2010 Semester, Department of Engineering, Indiana University-Purdue University Fort Wayne, October 2010.

4. M. Alhassan, Civil Engineering Program Assessment Report: Spring 2012 Semester, Department of Engineering, Indiana University-Purdue University Fort Wayne, September 2012. 


\section{Civil Engineering Program \\ Indiana University-Purdue University Fort Wayne \\ Lab Evaluation by}

\begin{tabular}{lll}
\hline Course \#: & CE381 & Course Title: Soils Mechanics Lab \\
\cline { 2 - 3 } Semester: & Spring & Year: 2013 \\
Instructor: & & Section: $01 \_$Number of Students: 14
\end{tabular}

Please indicate your overall experience with the labs that you took by circling a number.

$\begin{array}{cc}1 & 4 \\ \text { (strongly disagree) } & \text { (strongly agree) }\end{array}$

1. The lab is well equipped

$\begin{array}{llll}1 & 2 & 3 & 4\end{array}$

If not, what do you think is missing?

Direct Shear - per meability

Consolidation

Triaxial

Unconfided

2. The lab equipment is functional.

If not, please elaborate.

$\begin{array}{llll}1 & 2 & 3 & 4\end{array}$

Sieve shakes need to be fixed

3. The use of the lab equipment and facilities is safe If not, please elaborate.

$\begin{array}{llll}1 & 2 & 3 & 4\end{array}$

4. The lab technical support is adequate If not, please elaborate.

$\begin{array}{llll}1 & 2 & 3 & 4\end{array}$

5. The level and type of interactions with the lab technician

$\begin{array}{llll}1 & 2 & 3 & 4\end{array}$

is adequate

If not, please elaborate.

There is no lab technician

Figure 4: Student Assessment of the Lab 